\title{
Influence of semen on inflammatory modulators of embryo implantation
}

\author{
S.A. Robertson', S. O'Leary ${ }^{2}$ and D.T. Armstrong' \\ 'Research Centre for Reproductive Health, Department of Obstetrics and Cynaecology and \\ ${ }^{2}$ Department of Animal Sciences, University of Adelaide, SA 5005, Australia
}

Insemination transmits to the female reproductive tract constituents of seminal plasma that target uterine epithelial cells to activate a cascade of inflammatory and immunological changes. Experiments in rodents show seminal factor signalling acts to 'condition' the female immune response to tolerate the conceptus, and to organise molecular and cellular changes in the endometrium to facilitate embryo development and implantation. The active factors in seminal plasma are identified as members of the transforming growth factor- $\beta$ family, with the relative balance of active moieties influencing the precise character of the female tract response. Experiments in rodents show that disruption of seminal plasma priming causes foetal growth retardation and changes in placental structure, with long-term consequences for the growth of the neonate. Recent studies indicate a similar physiological function and molecular basis for seminal plasma actions in the pig. In gilts, seminal plasma elicits an endometrial response characterised by recruitment of inflammatory leukocytes and induction of several pro-inflammatory cytokines and cyclo-oxygenase-2. The consequences are evident throughout the pre-implantation period of early pregnancy with altered leukocyte populations and cytokine parameters seen for at least 9 days. Exposure to semen also alters the dynamics in pre-implantation embryo development with an increase in the number of embryos and in their viability. Furthermore seminal plasma influences the temporal kinetics of ovulation, corpus luteum development and steroid production in the ovary. Dissecting the actions of seminal plasma may facilitate development of strategies to ensure maximal fertility and reduce embryo mortality in the pig.

\section{Introduction}

Seminal plasma clearly has functions in the female reproductive tract beyond the conventionally recognised role in sperm transport and nutritive support. Recent studies in rodents and humans show that introduction of semen into the female tract elicits striking molecular and cellular changes with physiological consequences that promote the likelihood of embryo implantation and successful pregnancy. Active factors in seminal plasma bind to cognate recep- 
tors on target cells in the female reproductive tract, activating changes in gene expression leading to modifications in the cellular composition, structure and function of local tissues, as well as tissues distal to the tract including the ovary and peripheral lymphoid organs. This review will summarise our current understanding of the physiological role for seminal plasma in the mammalian female reproductive tract, drawing mostly from studies in the mouse and human, and will discuss evidence from our laboratory indicating a role for seminal plasma in establishing early pregnancy in the pig.

\section{The post-mating inflammatory cascade in mice and women}

The most immediate and clearly evident effect of insemination in mammals is a rapid and dramatic influx of inflammatory cells into the site of semen deposition. This 'post-mating inflammatory response' has been described most thoroughly in mice (De et al., 1991; McMaster et al., 1992; Robertson et al., 1996). The cellular changes are initiated when seminal plasma moieties interact with oestrogen-primed cervical and uterine epithelial cells to induce a surge in synthesis of pro-inflammatory cytokines including granulocyte-macrophage colony-stimulating factor (GM-CSF), interleukin (IL)-6 and an array of chemokines (Robertson et al., 1998; Robertson et al., 1996). These pro-inflammatory factors stimulate extravasation and infiltration of subepithelial stromal tissues with macrophages, dendritic cells, and granulocytes. In humans, intercourse elicits similar changes in the cervical tissue, characterised by neutrophil recruitment into the superficial epithelium of the cervical tissues (Pandya and Cohen, 1985) with a striking recruitment of macrophages, dendritic cells and lymphocytes into the epithelial layers and deeper stromal tissues (Robertson et al., 2001a).

\section{TGFß and other active factors in semen}

Experiments in mice from which accessory glands were surgically removed showed that the active inflammation-inducing moieties in semen are synthesised in the seminal vesicle, where the majority of seminal fluid is produced (Robertson et al., 1996). TGFß (comprising each of the mammalian isoforms $B 1, \beta 2$ and $B 3$ ) has been identified as the principal trigger for induction of uterine inflammatory responses following mating in mice (Robertson et al., 2002; Tremellen et al., 1998). The majority of the TGFß present in male seminal fluids is in the latent form, and appears to be activated in the female reproductive tract after insemination, by mechanisms presumably involving enzymatic cleavage or altering the conformation of latent TGFß to expose TGFB receptor binding sites (Robertson et al., 2002). TGFß is also identified as the principle active moiety in human semen in experiments using primary and transformed human cervical keratinocyte cultures (Gutsche et al., 2003; Sharkey and Robertson, 2004; Tremellen and Robertson, 1997). Seminal plasma is also rich in IL-8, which interacts with TGFß to further induce IL-1ß, IL-6 and LIF from human endometrial epithelial cells (Gutsche et al., 2003). Bacterial lipopolysaccharide introduced into the female tract at mating appears to synergise with endogenous seminal factors to induce cytokine synthesis in murine and human uterine and cervical epithelial cells, through binding to Toll-like receptors TLR2 and TLR4. Furthermore, we find that the type- 1 cytokine interferon- $\gamma$ acts as a potent inhibitor of TGFß signalling both in human and mouse epithelial cells (Glynn et al., 2004). Together this array of active seminal constituents appears to act in concert to stimulate expression of several cytokines in the female tract. Fluctuations in their relative proportions between individuals and even within an individual over time would result in variation in the pattern of cytokines activated in the fernale tissues, and thus the leukocyte composition of the ensuing inflammatory response. 


\section{Female tract responses activated by seminal plasma}

Seminal plasma is thought to impact on several downstream reproductive process in the female tract, via the agency of the large population of inflammatory leukocytes and through the cytokines that are induced by exposure to semen. Together the changes induced by seminal plasma act to promote oocyte fertilisation, embryo development and successful implantation. The effector functions postulated include; (1) clearance of superfluous sperm and microorganisms introduced into the uterus at mating; (2) activation of female immune responses specific to paternal transplantation proteins and other antigens present in semen; (3) tissue remodelling associated with preparation of endometrial receptivity; and (4) activation of expression of cytokines and growth factors implicated in pre-implantation embryo development (Fig. 1).

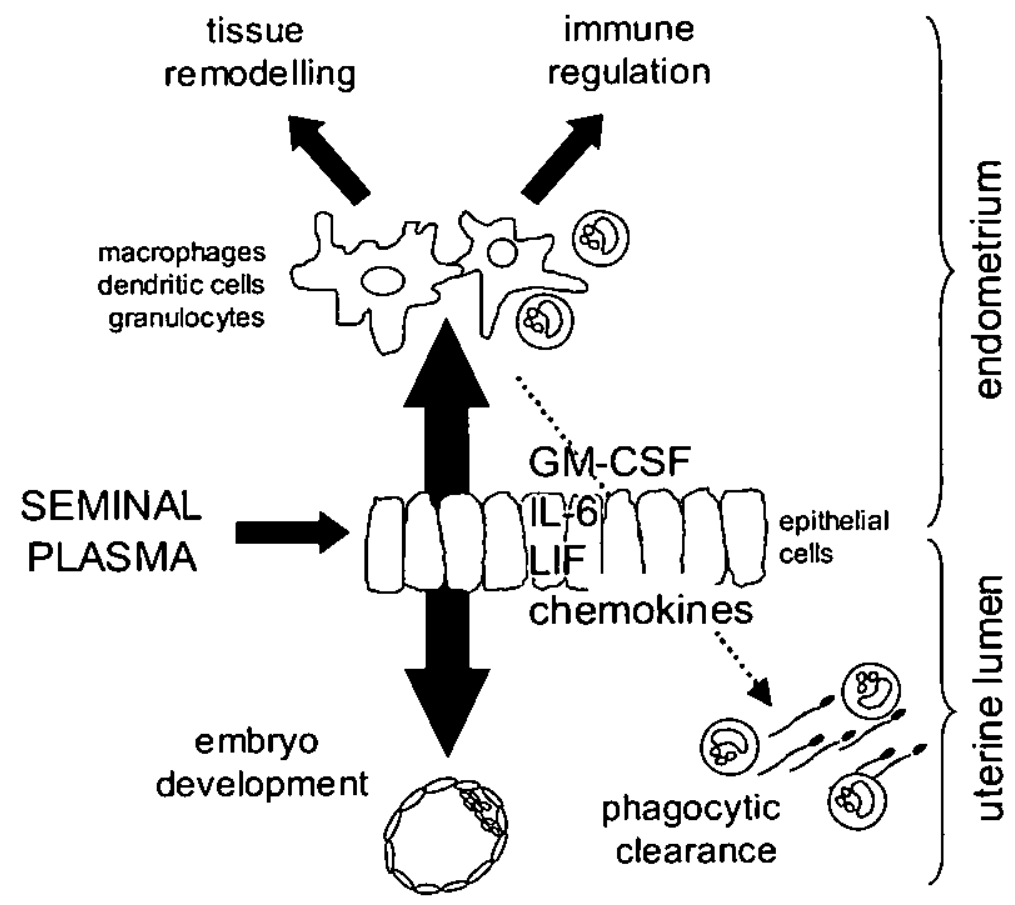

Fig. 1 Schematic diagram illustrating the action of seminal plasma signals in the female reproductive tract to facilitate embryo implantation, based upon emerging data in the mouse. At mating, active moieties in seminal fluid interact with epithelial cells in the cervix and uterus of the female reproductive tract to induce synthesis of pro-inflammatory cytokines including GM-CSF, IL-6 and other cytokines and chemokines. These pro-inflammatory cytokines cause the recruitment and activation of inflammatory cells in the endometrial stroma, including macrophages, dendritic cells and granulocytes. The macrophages and dendritic cells have roles in regulating tissue remodelling of the endometrial stroma and in activating maternal immune accommodation of pregnancy. Neutrophils traversing the endometrial epithelium into the luminal cavity have roles in clearing seminal debris to maintain uterine sterility. Epithelial cytokines activated by seminal plasma are also secreted into the luminal fluid where they exert embryotrophic actions on the developing pre-implantation embryo.

Maintenance of female tract sterility is one obvious role for the inflammatory leukocytes. The higher reproductive tract is normally sterile, with insemination providing the opportunity for 
access by commensal micro-organisms originating from male and female tissues, or sexually transmitted pathogens. Neutrophils that emigrate between epithelial cells into the uterine lumen act to phagocytose and clear micro-organisms and seminal debris remaining in the tract after intromission. Maintenance of a sterile female tract would facilitate sperm survival and the likelihood of the mating event resulting in pregnancy. Phagocytic cells in the cervix and uterus target spermatozoa as well as bacteria, but whether this is primarily to filter morphologically abnormal spermatozoa (Tomlinson et al., 1992) or alternatively to select sperm on the basis of other properties, remains unknown (Roldan et al., 1992).

\section{Seminal plasma and induction of maternal immune tolerance}

Hostile immune responses to seminal antigens would be incompatible with maintenance of fertility, and would prevent the female tract tolerating future semen exposures. There would also be consequences for pregnancy, since the conceptus shares paternal antigens with those in semen (Thaler, 1989). Avoidance of detrimental immunity to sperm antigens appears to be a function of seminal plasma, which activates immune responses that instead lead to immune tolerance of male antigens. Macrophages and dendritic cells recruited into the endometrial stromal tissue after exposure to semen (McMaster et al., 1992; Robertson et al., 1996) act to phagocytose and transport seminal antigens to draining lymph nodes, eliciting the first stages of activation of immune responses to paternal $\mathrm{MHC}$ and other antigens in semen (Beer and Billingham, 1974; Johansson et al., 2004; Piazzon et al., 1985). However the presence in seminal plasma of several powerful immuno-regulatory molecules such as PGE and TGFß acts to dampen potentially destructive Type-1 (cell-mediated) immune responses (Letterio and Roberts, 1998; Weiner, 2001), and to deviate the immune response towards immune tolerance. This is exemplified by experiments showing that female mice exposed to seminal plasma even in the absence of sperm or a conceptus show hypo-responsiveness in type 1 immunity to male $\mathrm{MHC}$ antigens and tolerate challenge with male tumour cells (Robertson et al., 1997).

We have further hypothesised that the female immune response to ejaculate antigens might also serve to activate cells that are subsequently recruited into the implantation site to facilitate early placental development (Robertson et al., 1997). In support of this, activated lymphocytes recovered from uterine draining lymph nodes after insemination can be radio-labelled and shown to traffic into the decidual tissues when transferred into pregnant recipient mice Johansson et al., 2004). Consistent with an immunological 'priming' function, exposure to semen of future male partners in mice promotes embryo implantation and foetal growth in a partnerspecific manner (Beer and Billingham, 1974; Robertson et al., 2003), and the priming effect is ablated when lymph nodes draining the uterus are removed (Beer et al., 1975; Tofoski and Gill, 1977).

\section{Seminal plasma regulation of endometrial receptivity for embryo implantation}

The leukocytes recruited after insemination potentially also exert tissue-remodelling effects in the uterus by secreting an array of potent enzymes and signalling molecules to affect extracellular matrix (ECM) turnover and vascular remodelling. In this way semen exposure is implicated in restructuring the endometrial environment to facilitate implantation and placental development. In particular, macrophages are likely to affect the behaviour of local endothelial cells, with their capacity to influence each phase of the angiogenic process, including alterations of the local extracellular matrix, induction of endothelial cells to migrate and proliferate, and formation of capillaries (Sunderkotter et al., 1994). The vascular endothelial growth factor 
(VEGF) family of genes are key angiogenic and vascular permeability-inducing agents implicated in the endometrial changes of early pregnancy (Ma et al., 2001). In other tissues, macrophages are recognised as the most prevalent source of VEGF (Yoshida et al., 1997) and as essential contributors to the angiogenic process (Aharinejad et al., 2004; Naidu et al., 2003). Consistent with a pro-angiogenic role for semen-induced macrophage infiltration, VEGF mRNA expression in hamsters is reduced after mating with accessory-gland deficient males (Chow et al., 2003).

An additional target for macrophage-secreted products is the ECM of the endometrial stroma, which is remodelled prior to and during decidualisation, with breakdown of existing matrix and the deposition of new components (Aplin, 2002). Matrix metalloproteinases (MMPs) regulate this process (Curry and Osteen, 2003; Das et al., 1997) after coordinated increases in their transcription, secretion and proteolytic activation, along with their regulatory proteins, the tissue inhibitors of metalloproteinases (TIMPs). Macrophages are a major source of a broad range of MMPs regulated by the influence of cytokines, ECM and prostaglandins (Goetzl et al., 1996). Semen-induced inflammatory cells appear to contribute to MMP regulation, since in golden hamsters the absence of male accessory gland fluids is associated with reduced expression of MMP-2 in the implantation site (Chow et al., 2003).

Macrophage mediators potentially also target the luminal epithelial cells involved in embryo attachment during the initial phase of implantation. Specific changes in epithelial cell expression of integrins and mucins allow close apposition and then adhesion between the blastocyst and the luminal surface (Aplin, 1997; Lessey et al., 1996), with fluctuating expression in adhesion and antiadhesion molecules providing a barrier until the window of implantation when the embryo becomes attached to the epithelium just prior to its invasion. Macrophages interdigitate between endometrial epithelial cells in a spatial association which suggests a role in influencing integrin expression at the paracrine level. Leukocyte regulation of epithelial adhesive properties has been demonstrated with human uterine epithelial cells in vitro (Kosaka et al., 2003). The ability of macrophages to alter transport properties and affect epithelial barrier integrity (Zareie et al., 1998) might further assist implantation by facilitating trophoblast breaching of the epithelial surface, and potentially contributes to the epithelial apoptosis which subsequently occurs.

\section{Seminal plasma induced synthesis of embryotrophic cytokines}

The cytokines induced after semen exposure are secreted into the epithelial glycocalyx and fluids of the uterine luminal space where they interact with the developing embryo as it traverses the oviduct and uterus prior to implantation. Several cytokines activated by semen are amongst those attributed with regulating proliferation, viability and differentiation of blastomeres in embryos (Kane et al., 1997; Pampfer et al., 1991). GM-CSF, a key cytokine induced during the post-mating inflammatory response, targets the pre-implantation embryo to promote blastocyst formation, increasing the number of viable blastomeres through inhibiting apoptosis and facilitating glucose uptake (Robertson et al., 2001b). Human embryos cultured in GM-CSF are twice as likely to reach the blastocyst stage of development, blastulate earlier and have increased cell numbers both in the inner cell mass and trophectoderm (Sjoblom et al., 1999). Other cytokines targeting the developing blastocyst including IL- 6 and LIF are similarly induced after exposure to semen (Gutsche et al., 2003; Robertson et al., 1992; S.A. Robertson, unpublished data). Perturbations in the growth factor environment experienced by the pre-implantation embryo impairs normal development of the placenta and foetus, with long term consequences for post-natal health and metabolic programming in progeny (Sjoblom et al., 2005). 


\section{Impact of seminal exposure on pregnancy outcome}

Artificial insemination (Al) with washed sperm or heavily diluted semen demonstrates that seminal plasma is not essential for initiation of pregnancy. However there is evidence that the success and quality of pregnancies are compromised in several species in which Al is practiced, particularly as measured by growth trajectory of the foetus. The most compelling data again come from rodents. Experiments in which the seminal vesicle, prostate or coagulating glands are surgically removed from mice, rats and hamsters prior to mating each show that seminal vesicle fluid is the most vital non-sperm component of the ejaculate, and support the interpretation that seminal plasma is essential for optimal sperm survival and fertilisation potential 10 et al., 1988; Pang et al., 1979; Peitz and Olds Clarke, 1986; Queen et al., 1981). In mice, embryo transfer protocols generally employ recipients exposed to seminal plasma by mating to vasectomised males, but foetal loss and abnormality is considerably greater when embryos are transferred after pseudopregnancy is achieved without exposure to male fluids (Watson et al., 1983). Confirmation that the effects of seminal plasma are mediated at least partly through promoting receptivity in the female tract comes from studies showing that when recipient females are mated with seminal vesicle deficient males, transferred embryos give rise to foetuses with impaired growth trajectories and altered placental development (Bromfield et al., 2004). In rats, implantation rates and foetal growth are similarly compromised unless females are inseminated prior to embryo transfer (Carp et al., 1984). Clinical studies in humans indicate there may be both acute and cumulative benefits of exposure to seminal constituents, and implicate a partner-specific route of action (Bellinge et al., 1986; Dekker et al., 1998; Tremellen et al., 2000).

\section{Effects of seminal plasma on uterine parameters in pigs}

The reproductive tract of the female pig, like that of the mouse, is exposed to large volumes of almost undiluted semen when the ejaculate is deposited directly into the uterine lumen (Lovell and Getty, 1968). Leukocytes including macrophages and dendritic cells, neutrophils, eosinophils and lymphocytes are present in the pig endometrium where their numbers fluctuate over the course of the cycle and during pregnancy (Bischof et al., 1995; Hussein et al., 1983; King, 1988). In pigs, as in mice and humans, exposure to seminal plasma elicits a dramatic increase in leukocyte recruitment, in a manner resembling a classical inflammatory response. Natural mating with a vasectomised boar (Bischof et al., 1994) and transcervical administration of seminal plasma (O'Leary et al., 2004) show that seminal plasma, as opposed to sperm, contains the factors acting to increase the numbers of inflammatory leukocytes in endometrial tissues and luminal fluids. As in the mouse and human response to semen, the endometrial infiltrate comprises principally macrophages and $\mathrm{MHC}$ class $\mathrm{II}^{+}$cells (Bischof et al., 1994; Engelhardt et al., 1997; O'Leary et al., 2004), and the luminal infiltrate comprises mainly neutrophils (Rozeboom et al., 1999; O'Leary et al., 2004). The response is accompanied by endometrial hypertrophy, and increased uterine vascularity, luminal fluid content and weight (Bischof et al., 1994; Engelhardt et al., 1997; O'Leary et al., 2004). Tracts exposed to semen contain relatively more macrophages and inflammatory cells compared with untreated animals for up to nine days after mating (O'Leary et al., 2004), however the vascular indices of inflammation subside more quickly.

Quantitative RT-PCR experiments indicate that the uterine inflammatory response in pigs is driven by induction of similar pro-inflammatory mediators to those seen in mice and women. GM-CSF, IL-6 and MCP-1 are the key cytokines induced after seminal plasma exposure and are accompanied by upregulated COX-2 mRNA expression (O'Leary et al., 2004)(Fig. 2), but these are likely to be only some of a broader repertoire of inflammatory cytokines, chemokines and 
other mediators. Their temporal pattern of expression parallels the response seen in mice, with a transient pulse in expression then subsequent decline. Interestingly, the consequences of seminal plasma exposure persist over the course of the pre-implantation period, with reduced expression of GM-CSF and the pro-inflammatory mediator COX-2 five days after treatment with seminal plasma and extended semen, and reduced expression of MCP-1 nine days later. The mechanisms by which exposure to seminal components influence the longer-term pattern of cytokine expression are not clear, but may be related to the effects of seminal constituents on ovarian progesterone synthesis (see below). Early pregnancy factor (EPF), a member of the chaperonin 10 family of molecules with potent immunosuppressive properties, has been shown to be increased after mating sows with vasectomised boars (Koch and Ellendorff, 1985) and might also facilitate rapid resolution of endometrial inflammation.

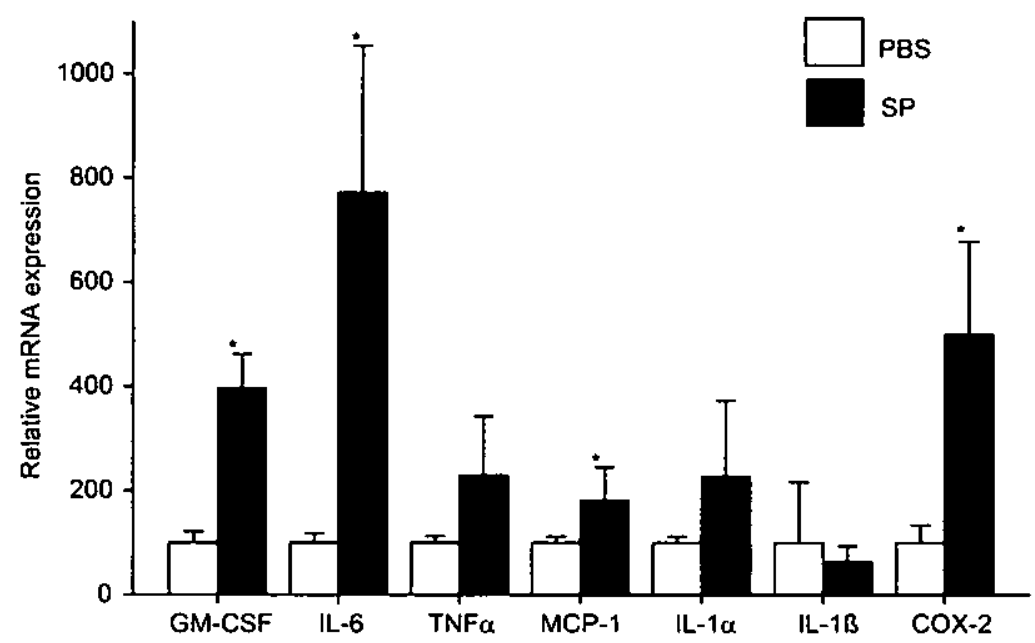

Fig. 2 Effect of seminal plasma (SP) on endometrial expression of mRNAs encoding proinflammatory cytokines and COX-2. Endometrial tissue was recovered at autopsy from gitts $34 \mathrm{~h}$ after transcervical infusion of seminal plasma or PBS, as described ( $O^{\prime}$ Leary et al., 2004). Cytokine mRNA expression was quantified by real-time quantitative RT-PCR and normalised to B-actin mRNA content, and is presented as means \pm SEM relative mRNA expression after ascribing an arbitrary value of 100 to the mean value in the PBS group. Effect of treatment was analysed by Kruskal-Wallis followed by Mann-Whitney U-test; * $P$ $<0.05$.

Little is known about the physiological significance of the inflammatory cells and cytokines induced by seminal plasma in terms of their effects on uterine receptivity to embryo implantation and pregnancy. The post-mating inflammatory response is likely to promote recovery of uterine sterility, and the potential importance of rapid resolution of the uterine inflammatory response is shown in studies linking use of seminal plasma with implantation success (Rozeboom et al., 2000). Furthermore, the post-mating inflammatory response has been shown to result in activation and expansion of lymphocyte populations in draining lymph nodes (Bischof et al., 1994), giving rise to cell populations that potentially exert effects later in pregnancy. There are additional pathways through which inflammatory cells might exert effects on the endometrial environment, but to date these are unexplored. In the pig, as in other species, macrophages are implicated as key cells in tissue remodelling events and so effects on vascular supply and permeability, epithelial integrin expression and extracellular matrix composition can be envis- 
aged. Induction of endometrial COX-2 expression by seminal factors has several potential consequences since COX-2 catalyses the formation of prostaglandins $\mathrm{PGF}_{2 \alpha}$ and $\mathrm{PGE}_{2}$. These prostaglandins have pleiotrophic effects in pregnancy and their synthesis in the uterus has the potential to influence maternal immune responses (Kelly and Critchley, 1997), embryo development (Claus et al., 1987) and ovarian function (Armstrong, 1981; Christenson et al., 1994).

\section{Effects of seminal plasma on embryo development in pigs}

The quality of the uterine environment is a well-recognised factor in embryo viability and development in pigs (Pope et al., 1990; Vallet et al., 2002). Treatment of gilts with seminal plasma has been shown to increase the numbers of viable embryos and to alter embryo growth trajectory during the pre-implantation period (O'Leary et al., 2004). Surprisingly, the increased number of viable blastocysts retrieved from the tract on day nine of pregnancy was associated with significant reduction in their average size, suggesting seminal conditioning of the tract may act to promote embryo survival while constraining their pace of development.

The increase in embryo survival presumably reflects indirect effects of seminal constituents on the reproductive tract environment acting to reduce early embryo mortality, most likely through effects on local epithelial cell cytokine synthesis. Several cytokines can influence preimplantation embryo development, acting both to promote and restrict blastocyst growth and to co-ordinate synchronous development with the maternal tract (Jaeger et al., 2001). GM-CSF is one important embryotrophic molecule, and its enhanced expression in response to seminal plasma is likely to increase the GM-CSF reservoir associated with glycosaminoglycans in the epithelial glycocalyx (Roberts et al., 1988). The growth promoting effects of GM-CSF for embryo development to blastocyst stage have been described in mice (Robertson et al., 2001b), cattle (de Moraes and Hansen, 1997) and in humans (Sjoblom et al., 1999), and in ovine embryos, GM-CSF acts to stimulate secretion of interferon- $\tau$ (Imakawa et al., 1993). The extent to which GM-CSF as opposed to other embryotrophic cytokines and growth factors might account for the effect of semen in pig embryo development remains to be examined, and in vitro embryo culture experiments will assist in this endeavour.

Whether limiting the rate of blastocyst expansion is linked with enhanced embryo survival is unclear, but it is relevant that similar mechanisms are purported to increase embryo survival in Meishan pigs. Compared with commercial breeds, Meishan pigs have smaller embryos with fewer cells during the blastocyst stage (Rivera et al., 1996), and unique uterine-embryo signalling in Meishans is believed to underpin a maternal ability to control embryo growth resulting in the prolificacy of this breed (Christenson et al., 1993). Asynchronous development of embryos within a cohort is identified a key determinant of poor implantation success, with advanced embryos restricting development of their retarded counterparts (Pope et al., 1982). It is reasonable to suggest that the effects of seminal plasma might serve to increase uniformity in embryo development.

\section{Effects of semen on ovulation, corpus luteum development and progesterone synthesis in pigs}

Another potentially important role for seminal plasma in the pig has been identified in regulating ovarian function. Both natural mating (Signoret et al., 1972) and transcervical administration of seminal plasma (Waberski et al., 1995; Weitze et al., 1990) at the beginning of oestrus have been shown to advance the onset of ovulation by up to 14 hours. This effect on ovulation may serve to promote synchronous development within a cohort of embryos by restricting the duration of ovulation (O'Leary et al., 2002). 
Events surrounding luteinisation are potentially also affected by seminal constituents. We have investigated the effect of intrauterine seminal plasma exposure on corpus luteum development and ovarian steroidogenesis. Plasma progesterone levels were higher and peaked earlier in gilts treated with seminal plasma (O'Leary et al., 2002). This was associated with an increase in corpora lutea size, suggesting that the number and output of steroidogenic luteal cells is greater in animals exposed to seminal components. This result was mirrored by in vitro experiments, where enhanced progesterone secretion in response to gonadotrophins and growth factors was observed in cultures of granulosa cells from gilts exposed to seminal plasma (Armstrong, 1999). Effects mediated through the agency of leukocytes potentially explain this, since immunohistochemical studies show a greater abundance of predominantly $\mathrm{MHC}$ class ॥ positive macrophages and/or dendritic cells in the stromal tissues and thecal cells associated with pre-and peri-ovulatory follicles in seminal plasma treated animals. In vitro culture experiments and studies in cytokine null mutant mice support the postulate that cytokines or other mediators originating from these cells facilitate proliferation and/or functional activation of steroidogenic cells (Cohen et al., 1997; Jasper et al., 2000).

Elevated progesterone in early pregnancy is known to have beneficial consequences for pregnancy. Nutritionally-induced upregulation of progesterone early in pregnancy has been associated with improved embryonic survival (Almeida et al., 2000; Jindal et al., 1997). The effect is likely to be due to the influence of progesterone in uterine tissues, presumably acting directly to promote endometrial transformation or indirectly through secretion of embryotrophic growth factors. Elevated synthesis of progesterone after exposure to seminal plasma might partially explain the persisting effects of seminal plasma exposure on endometrial cytokine expression over the pre-implantation period of early pregnancy.

The mechanisms by which seminal plasma exerts effects in the ovary remains unknown. Studies in which uterine horns are unilaterally ligated show that the effects are not mediated systemically, and instead implicate a local communication pathway between the uterine horn and the adjacent ovary (Waberski et al., 1995). PGF ${ }_{2 \alpha}$ and PGE, known to be induced in the endometrium by seminal plasma oestrogens (Claus, 1990) and facilitated by upregulated COX2 expression ( $O^{\prime}$ Leary et al., 2004), are likely candidates in influencing follicular development and rupture (Armstrong, 1981) and have clearly been implicated in regulating luteal development in the maternal recognition of pregnancy (Bazer and Thatcher, 1977). Since neither of these agents administered transcervically could advance ovulation (Waberski et al., 1995), an alternative vascular route has been advanced. Interestingly, endometrial prostaglandins have been shown to reach the ovary by a route believed to involve a unique counter current exchange (Claus, 1989) facilitated by close apposition of the uterine venous net to the ovarian artery (Krzymowski et al., 1989). In non-mated gilts $\mathrm{PGF}_{2 \alpha}$ is the major eicosanoid but in mated gilts peak prostaglandin secretion occurs earlier and $\mathrm{PGE}_{2}$ predominates, antagonising the luteolytic effects of $\mathrm{PGF}_{2 \alpha}$ (Christenson et al., 1994). The increase in COX-2 mRNA after exposure to seminal plasma thus raises the tantalising possibility of a new role for seminal plasma in amplifying uterine-derived prostaglandin signals which act to precipitate ovulation, exert anti-luteolytic effects and increase progesterone synthesis (Fig. 3).

\section{Active constituents in pig semen}

Less is known about the active constituents of pig seminal plasma than those in rodents and humans. The content of TGFß in porcine seminal plasma is similar to the high levels measured in human and murine seminal plasma (Robertson et al., 2002) and TGFß thus is implicated as a key mediator of the effects of boar seminal plasma. Seminal plasma in pigs contains similarly 
high levels of TGFß: [median (range) $-150(28-495) \mathrm{ng} / \mathrm{ml} \mathrm{TGFB1}$ and $123(96-144) \mathrm{ng} / \mathrm{ml}$ TGFß2; n - 23] (S. O'Leary, S.A. Robertson and D.T. Armstrong, unpublished data). Given that the average volume of boar ejaculate is $300 \mathrm{ml}$ and that this would be diluted less than two-fold in the female tract after mating, TGFß in the female tract would attain concentrations at the high end of the physiological range. There is greater equivalence between the content of the two isoforms, with a higher content of TGFB2 in pig seminal plasma than in mice or human. TGF $B$ in pig seminal plasma also shows the unusual characteristic of being almost exclusively present in the biologically active form, whereas in mice and humans, seminal TGFB is principally latent and is activated in the female tract. As in humans, the concentration of TGFB in boar semen fluctuates minimally over time, but interestingly, repeated mating at daily intervals is associated with declining content over the course of a week (S. O'Leary, S.A. Robertson and D.T. Armstrong, unpublished data).

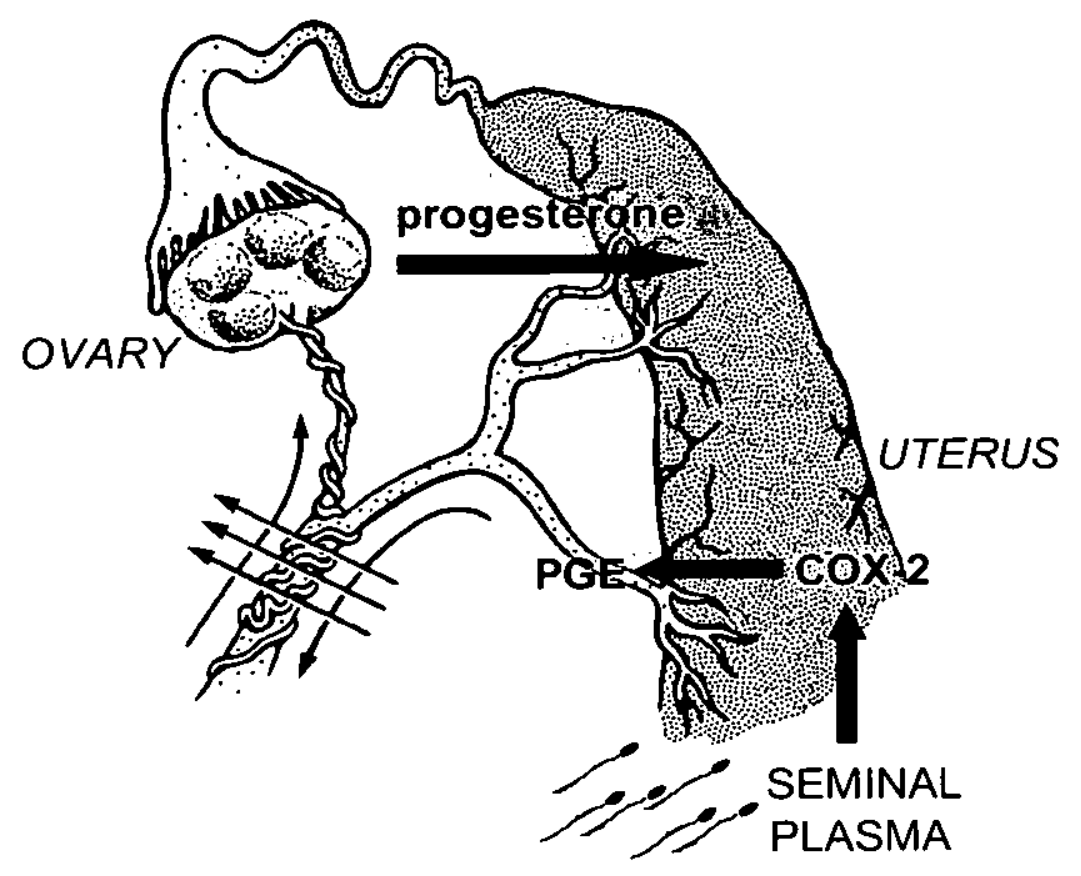

Fig. 3 Schematic diagram illustrating the action of seminal plasma signals in the female reproductive tract to promote corpus luteum development in the ovary. Seminal plasma acts in the endometrial tissue of gilts to increase COX-2 mRNA expression. This is postulated to promote uterine synthesis of prostaglandins PGE and $P G F_{2 u^{\prime}}$ which access the ovary via a vascular counter-current system to promote corpus luteum development and progesterone synthesis.

Our recent studies in mouse and human semen indicate that lipopolysaccharide derived from gram negative bacteria is an important additional agent acting in synergy with other seminal moieties. Bacteria originating from the male reproductive tissues and from the lower regions of the female reproductive tract access the higher reproductive tract at insemination. In particular, we have been interested in the potential role of commensal bacteria of the Lactobacillus genus, which are implicated in beneficial 'probiotic' roles in the gut and other mucosal tissues. We have recently reported that Lactobacilli are present in abundance in boar seminal plasma compared with other potentially pathogenic bacteria (Sivaramakrishnan et al., 2004). By analogy 
with their roles in other mucosal tissues, their presence in semen is likely to reduce the incidence of pathogenic infections, both passively and via production of anti-microbial substances, and through Toll-like receptor-mediated activation of cytokine expression in the uterine epithelium. Lactobacilli potentially also act to assist in latent TGFß cleavage through increasing local $\mathrm{pH}$, and through the hydrolytic cleavage or de novo generation of immunoregulatory peptides from seminal substrates.

\section{Practical applications in the pig industry and future directions}

Embryonic loss during the pre- and peri-implantation period is a major limitation on litter size in pigs where between $30 \%$ and $40 \%$ of fertilised ova do not result in a live born piglet (Dzuik, 1987). Artificial insemination results in fewer live born offspring than natural mating (Skjervold, 1975), and since there is no reduction in fertilisation rate even after extensive dilution of semen, it is reasonable to propose that the difference is due to effects of seminal plasma acting on the endometrial and ovarian tissues. Interventions involving exposure to seminal constituents have met with some success in reducing early loss, for example mating with a vasectomised male or administration of heat-killed semen restores litter size and improves farrowing rate (Mah et al., 1985; Murray and Grifo, 1986), and addition of seminal plasma to sperm at artificial insemination is reported to increase conception and farrowing rates (Rozeboom et al., 2000). Pre-sensitisation of the uterus to sperm and seminal antigens in a previous oestrous cycle also increased litter size in gilts (Murray et al., 1983). Similar effects were observed in pigs when antigenic stimulation by addition of leukocyte antigens to semen at breeding was reported to increase embryo survival measured in the fifth week of pregnancy (Almlid, 1981).

Studies in mice and humans show clearly that seminal plasma can no longer be considered simply a sperm transport medium, but instead must be recognised as a means for communication between the male and female reproductive tissues, and a necessary agent for conditioning of the female tract for optimal pregnancy success. The data reviewed herein on the molecular and cellular consequences of seminal plasma action in the female tract in pigs clearly show that specific constituents of seminal plasma regulate the cytokine and leukocyte environment in early pregnancy and begin to provide a molecular explanation for the beneficial effects of semen exposure in increasing litter size in pigs. Strategies that utilise immuno-stimulatory molecules in seminal plasma might thus provide an effective method for improving reproductive efficiency in the pig and other species. In the future, it seems reasonable that constituents of seminal plasma could be incorporated in semen extender formulations to replicate the natural effects of seminal plasma at artificial insemination. Similarly, the potential value of improving reproductive performance by administration of Lactobacilli or other probiotic agents needs to be examined. However, further studies are required to characterise the active components in seminal plasma and to determine whether these can be exploited to improve reproductive outcome in the pig industry.

\section{Acknowledgements}

The authors acknowledge the support of Australian Pork Limited, and the NHMRC of Australia Fellowship and Program Grant schemes.

\section{References}

Aharinejad S, Paulus P, Sioud M, Hofmann M, Zins K, Schafer R, Stanley ER and Abraham D (2004) Colonystimulating factor- 1 blockade by antisense oligonucle- otides and small interfering RNAs suppresses growth of human mammary tumor xenografts in mice Cancer Research 64 5378-5384. 
Almeida FR, Kirkwood RN, Aherne FX and Foxcroft GR (2000) Consequences of different patterns of feed intake during the estrous cycle in gilts on subsequent fertility Journal of Animal Science 78 15561563.

Almlid (1981) Does enhanced antigenicity of semen increase the litter size in pigs? Journal of Animal Breeding and Genetics 98 1-10.

Aplin JD (1997) Adhesion molecules in implantation Reviews in Reproduction 2 84-93.

Aplin JD (2002) Endometrial Extracellular Matrix. In The Endometrium pp. 294-307 Eds JA SR Glasser, LC Guidice and S Tabibzadeh. Taylor and Francis: London and New York

Armstrong DT (1981) Prostaglandins and follicular functions fournal of Reproduction and Fertility 62 283291.

Armstrong DT (1999) Effects of intrauterine seminal plasma on responses of pig follicles to gonadotrophin hormones and growth factors. In 'Manipulating Pig Production: Proceedings of the Conference of the Australian Pig Science Association'. p 102.

Bazer FW and Thatcher WW (1977) Theory of maternal recognition of pregnancy in swine based on estrogen controlled endocrine versus exocrine secretion of prostaglandin F2alpha by the uterine endometrium Prostaglandins $14397-400$.

Beer AE and Billingham RE (1974) Host responses to intra-uterine tissue, cellular and foetal allografts lournal of Reproduction and Fertility Supplement 2159 88.

Beer AE, Billingham RE and Scott JR (1975) Immunogenetic aspects of implantation, placentation and fetoplacental growth rates Biology of Reproduction 126, 176-189.

Bellinge BS, Copeland CM, Thomas TD, Mazzucchelli RE, O'Neil G and Cohen MJ (1986) The influence of patient insemination on the implantation rate in an in vitro fertilization and embryo transfer program Fertility and Sterility 46 2523-2526.

Bischof R], Brandon MR and Lee CS (1995) Cellular immune responses in the pig uterus during pregnancy lournal of Reproductive Immunology 29 161178.

Bischof Rj, Lee CS, Brandon MR and Meeusen E (1994) Inflammatory response in the pig uterus induced by seminal plasma Journal of Reproductive Immunology 26 131-146.

Bromfield JJ, Roberts CT and Robertson SA (2004) Seminal plasma programs uterine receptivity and pregnancy outcome Biology of Reproduction 37th Annual Meeting of the Society for the Study of Reproduction 94.

Carp HJ, Serr DM, Mashiach S and Nebel L (1984) Influence of insemination on the implantation of transferred rat blastocysts Gynecoogical and Obstetric investigation 18, 194-198.

Chow PH, Jiang HY, Poon HK, Lee KH and O WS (2003) Embryos sired by males without accessory sex glands induce failure of uterine support: a sludy of VEGF, MMP and TGF expression in the golden hamster
Anatomy and Embryology (Berlin) 206 203-213.

Christenson LK, Farley DB, Anderson LH and Ford SP (1994) Luteal maintenance during early pregnancy in the pig: role for prostaglandin E2 Prostaglandins 4761.75.

Christenson RK, Vallet JL, Leymaster KA and Young LD (1993) Uterine function in Meishan pigs Journal of Reproduction and Fertility Supplement 48 279-289.

Claus R (1989) Oestrogens of the boar: effects on male and female reproductive function. In Reproductive Biology and Medicine pp. 136-147 Eds AF Holstein, KD Voight and D Grasslin. Diesbach Verlag, Berlin.

Claus R (1990) Physiological role of seminal components in the reproductive tract of the female pig Journal of Reproduction and Fertility Supplement $\mathbf{4 0}$ 117-131.

Claus R, Hoang-Vu C, Ellendorff F, Meyer HD, Schopper $D$ and Weiler $U$ (1987) Seminal oestrogens in the boar: origin and functions in the sow Journal of Steroid Biochemistry 27 331-335.

Cohen PE, Zhu L and Pollard JW (1997) Absence of colony stimulating factor- 1 in osteopetrotic (csfmop/ csf́m ${ }^{\circ p}$ ) mice disrupts estrous cycles and ovulation Biology of Reproduction 56 110-118.

Curry TE, Ir. and Osteen KG (2003) The matrix metalloproteinase system: changes, regulation, and impact throughout the ovarian and uterine reproductive cycle Endocrine Reviews 24 428-465.

Das SK, Yano S, Wang J, Edwards DR, Nagase $H$ and Dey SK (1997) Expression of matrix metallo-proteinases and tissue inhibitors of metalloproteinases in the mouse uterus during the peri-implantation period Developmental Genetics 21 44-54.

De $M$, Choudhuri R and Wood GW (1991) Determination of the number and distribution of macrophages, lymphocytes, and granulocytes in the mouse uterus from mating through implantation fournal of Leukocyte Biology 50 252-262.

de Moraes AA and Hansen PJ (1997) Granulocyte-macrophage colony-stimulating factor promotes development of in vitro produced bovine embryos Biology of Reproduction 57 1060-1065.

Dekker GA, Robillard PY and Hulsey TC (1998) Immune maladaptation in the etiology of preeclampsia: a review of corroborative epidemiologic studies Obstetrics and Gynaecological Survey 53 377-382.

Dzuik PJ (1987) Embryonic loss in the pig: an enigma. In Manipulating Pig Production: Proceedings of the Conference of the Australian Pig Science Association'. (Ed. Jl. Barnett) pp. 28-39. (Frankland Pty. Ltd.: Melbourne)

Engelhardt H, Croy BA and King GJ (1997) Role of uterine immune cells in early pregnancy in pigs Journal of Reproduction and Fertility Supplement 52 115131.

Glynn DJ, Sharkey DJ and Robertson SA (2004) Interferon-gamma inhibits female reproductive tract responsiveness to seminal plasma Biology of Reproduction 37th Annual Meeting of the Society for the Study of Reproduction 242.

Goetzl EJ, Banda MJ and Leppert D (1996) Matrix 
metalloproteinases in immunity fournal of immunology 156 1-4.

Gutsche S, von Wolff $M$, Strowitzki T and Thaler CJ (2003) Seminal plasma induces mRNA expression of IL-1 beta, IL-6 and LIF in endometrial epithelial cells in vitro Molecular Human Reproduction 9 785-791.

Hussein AM, Newby TJ and Bourne FJ (1983) Immunohistochemical studies of the local immune system in the reproductive tract of the sow Journal of Reproductive Immunology 5 1-15.

Imakawa K, Helmer SD, Nephew KP, Meka CS and Christenson RK (1993) A novel role for GM-CSF: enhancement of pregnancy specific interferon production, ovine trophoblast protein-1 Endocrinology 132 1869-1871.

Jaeger LA, Johnson GA, Ka H, Garlow JG, Burghardt RC, Spencer TE and Bazer FW (2001) Functional analysis of autocrine and paracrine signalling at the uterine-conceptus interface in pigs Reproduction Supplement 58 191-207.

Jasper MJ, Robertson SA, Van der Hoek KH, Bonello $\mathrm{N}$, Brannstrom $M$ and Norman RJ (2000) Characterization of ovarian function in granulocyte-macrophage colony-stimulating factor-deficient mice Biology of Reproduction 62 704-713.

Jindal R, Cosgrove JR and Foxcroft GR (1997) Progesterone mediates nutritionally induced effects on embryonic survival in gilts Journal of Animal Science 75 1063-1070.

Johansson M, Bromfield J, Jasper MJ and Robertson SA (2004) Semen activates the female immune response during early pregnancy in mice Immunology 112 290-300.

Kane MT, Morgan PM and Coonan C (1997) Peptide growth factors and preimplantation development Human Reproduction Update 3 137-157.

Kelly RW and Critchley HO (1997) Immunomodulation by human seminal plasma: a benefit for spermatozoon and pathogen? Human Reproduction 12 22002207.

King C) (1988) Reduction in uterine intra-epithelial lymphocytes during early gestation in pigs lournal Reproductive Immunology 14 41-6.

Koch $E$ and Ellendorff F (1985) Detection of activity similar to that of early pregnancy factor after mating sows with a vasectomized boar Journal of Reproduction and Fertility 74 39-46.

Kosaka K, Fujiwara H, Tatsumi K, Yoshioka S, Higuchi T, Sato $Y$, Nakayama T and Fujii S (2003) Human peripheral blood mononuclear cells enhance cell-cell interaction between human endometrial epithelial cells and BeWo-cell spheroids Human Reproduction 18 19.25.

Krzymowski T, Stefanczyk-Krzymowska $S$ and Koziorowski M (1989) Counter current transfer of PGF2 alpha in the mesometrial vessels as a mechanism for prevention of luteal regression in early pregnancy Acta Physiology Poland 40 23-34.

Lessey BA, Ilesanmi AO, Lessey MA, Riben M, Harris JE and Chwalisz K (1996) Luminal and glandular endometrial epithelium express integrins differentially throughout the menstrual cycle: implications for implantation, contraception, and infertility American lournal of Reproductive Immunology 35 195-204.

Letterio JJ and Roberts AB (1998) Regulation of immune responses by TGF-beta AnnualReviews of $\mathrm{Im}$ munology 16 137-161.

Lovell JW and Getty R (1968) Fate of semen in the uterus of the sow: histologic study of endometrium during the 27 hours after natural service American Journal of Veterinary Research 29 609-625.

Ma W, Tan J, Matsumoto H, Robert B, Abrahamson DR, Das SK and Dey SK (2001) Adult tissue angiogenesis: evidence for negative regulation by estrogen in the uterus Molecular Endocrinology 151983. 1992.

Mah J, Tilton JE, Williams GL, Johnson JN and Marchello M) (1985) The effect of repeated mating at short intervals on reproductive performance of gilts fournal of Animal Science 60 1052-1054.

McMaster MT, Newton RC, Dey SK and Andrews GK (1992) Activation and distribution of inflammatory cells in the mouse uterus during the preimplantation period fournal of Immunology 148 1699-1705.

Murray FA, Grifco P and Parker CF (1983) Increased litter size in gilts by intrauterine infusion of seminal and sperm antigens before mating fournal of Reproductive Immunology 56 895-900.

Murray FA and Grifo AP, Ir. (1986) Intrauterine infusion of killed semen to increase litter size in gilts fournal of Animal Science 62 187-190.

Naidu BV, Krishnadasan B, Farivar AS, Woolley SM, Thomas R, Van Rooijen N, Verrier ED and Mulligan MS (2003) Early activation of the alveolar macrophage is critical to the development of lung ischemiareperfusion injury lournal of Thorasic and Cardiovascular Surgergy 126 200-207.

$O$ WS, Chen HQ and Chow PH (1988) Effects of male accessory sex gland secretions on early embryonic development in the golden hamster fournal of Reproduction and Fertility 84 341-344.

O'Leary S, Jasper MJ, Warnes GM, Armstrong DT and Robertson SA (2004) Seminal plasma regulates endometrial cytokine expression, leukocyte recruitment and embryo development in the pig Reproduction 128 237-247.

O'Leary S, Robertson SA and Armstrong DT (2002) The influence of seminal plasma on ovarian function in pigs - a novel inflammatory mechanism? journal of Reproductive Immunology 57 225-238.

Pampfer S, Arceci RJ and Pollard JW (1991) Role of colony stimulating factor-1 (CSF-1) and other lymphohematopoietic growth factors in mouse pre-implantation development Bioessays 13 535-540.

Pandya IJ and Cohen J (1985) The leukocytic reaction of the human cervix to spermatozoa Fertility and Sterility 43 417-421.

Pang SF, Chow PH and Wong TM (1979) The role of the seminal vesicle, coagulating glands and prostate glands on the fertility and fecundity of mice journal of Reproduction and Fertility 56 129-132.

Peitz B and Olds Clarke P (1986) Effects of seminal vesicle 
removal on fertility and uterine sperm motility in the house mouse Biology of Reproduction 35 608617.

Piazzon I, Matusevich $M$, Deroche A, Nepomnaschy I and Pasqualini CD (1985) Early increase in graftversus-host reactivity during pregnancy in the mouse Journal Reproductive Immunology 8 129-137.

Pope WF, Mauer RR and Stormshak F (1982) Survival of porcine embryos after asynchronous transfer. Proceedings of the Society of Experimental Biology and Medicine 171 179-183.

Pope WF, Xie S, Broermann DM and Nephew KP (1990) Causes and consequences of early embryonic diversity in pigs lournal of Reproduction and Fertility Supplement $40251-260$.

Queen F, Dhabuwala CB and Pierrepoint CG (1981) The effect of removal of the various accessory sex glands on the fertility of male rats Journal of Reproduction and Fertility 62 423-436.

Rivera RM, Youngs CR and Ford SP (1996) A comparison of the number of inner cell mass and trophectoderm cells of preimplantation Meishan and Yorkshire pig embryos at similar developmental stages journal of Reproduction and Fertility 106 111-116.

Roberts R, Gallagher J, Spooncer E, Allen TD, Bloomfield F and Dexter TM (1988) Heparan sulphate bound growth factors: a mechanism for stromal cell mediated haemopoiesis Nature 332 376-378.

Robertson SA, Allanson $M$ and Mau VJ (1998) Molecular regulation of uterine leukocyte recruitment during early pregnancy in the mouse Trophoblast Research 11 101-120.

Robertson SA, Bromfield J and Tremellen KP (2003) Seminal 'priming' for protection from pre-eclampsia-a unifying hypothesis Journal of Reproductive immunology 59 253-265.

Robertson SA, Ingman WV, O'Leary S, Sharkey DJ and Tremellen KP (2002) Transforming growth factor betaa mediator of immune deviation in seminal plasma lournal of Reproductive Immunology 57 109-128.

Robertson SA, Mau VJ, Hudson SA and Tremellen KP (1997) Cytokine-leukocyte networks and the establishment of pregnancy American Journal of Reproductive Immunology 37 438-442.

Robertson SA, Mau VI, Tremellen KP and Seamark RF (1996) Role of high molecular weight seminal vesicle proteins in eliciting the uterine inflammatory response to semen in mice Journal of Reproduction and Fertility 107 265-277.

Robertson SA, Mayrhofer G and Seamark RF (1992) Uterine epithelial cells synthesize granulocyte-macrophage colony-stimulating factor and interleukin- 6 in pregnant and nonpregnant mice Biology of Reproduction 46 1069-1079.

Robertson SA, Sharkey D), Tremellen KP and Danielsson KG (2001a) Semen elicits immunological changes in the human cervix fournal of the Society for Cynecological Investigation $9228 \mathrm{~A}$.

Robertson SA, Sjoblom C, Jasper MJ, Norman RJ and Seamark RF (2001b) Granulocyte-macrophage colonystimulating factor promotes glucose transport and blastomere viability in murine preimplantation embryos Biology of Reproduction 64 1206-1215.

Roldan ER, Gomendio $M$ and Vitullo AD (1992) The evolution of eutherian spermatozoa and underlying selective forces: female selection and sperm competition Biological Reviews of the Cambridge Philosophical Society $67551-593$.

Rozeboom KJ, Troedsson $\mathrm{MH}$, Hodson $\mathrm{HH}$, Shurson GC and Crabo BG (2000) The importance of seminal plasma on the fertility of subsequent artificial inseminations in swine fournal of Animal Science 78 443. 448 .

Rozeboom KJ, Troedsson MH, Molitor TW and Crabo BG (1999) The effect of spermatozoa and seminal plasma on leukocyte migration into the uterus of gilts Journal of Animal Science 77 2201-2206.

Sharkey DI and Robertson SA (2004) Seminal plasma TGFbeta activates pro-inflammatory cytokine synthesis in human cervical epithelial cells Reproduction, Fertility and Development 16 (supplement), 80.

Signoret IP, Du Mesnil du Buisson $F$ and Mauleon $P$ (1972) Effect of mating on the onset and duration of ovulation in the sow fournal of Reproduction and Fertility $31327-330$.

Sivaramakrishnan G, Jasper MJ, $O^{\prime}$ Leary $S$ and Robertson SA (2004) Probiotic lactobacillus in semen. Reproduction, Fertility and Development 16 (supplement), 95.

Sjoblom C, Roberts CT, Wikland $M$ and Robertson SA (2005) GM-CSF alleviates adverse consequences of embryo culture on foetal growth trajectory and placental morphogenesis Endocrinology 146 2142-2153.

Sjoblom C, Wikland $M$ and Robertson SA (1999) Granulocyte-macrophage colony-stimulating factor promotes human blastocyst development in vitro $\mathrm{Hu}$ man Reproduction 14 3069-3076.

Skjervold $\mathbf{H}$ (1975) Comparison of litter size by use of natural and artificial mating Journal of Animal Breeding and Genetics 92 252-259.

Sunderkotter C, Steinbrink K, Goebeler M, Bhardwaj R and Sorg $C$ (1994) Macrophages and angiogenesis Journal of Leukocyte Biology 55 410-422.

Thaler C) (1989) Immunological role for seminal plasma in insemination and pregnancy American Journal of Reproductive Immunology 21 147-150.

Tofoski JG and Gill TJ-r (1977) The production of migration inhibitory factor and reproductive capacity in allogeneic pregnancies American Journal of Pathology 88 333-344.

Tomlinson M), White A, Barratt CL, Bolton AE and Cooke ID (1992) The removal of morphologically abnormal sperm forms by phagocytes: a positive role for seminal leukocytes? Human Reproduction 7517 522.

Tremellen KP and Robertson SA (1997) Potential role of seminal plasma TCFB in the initiation of the postcoital inflammatory response in humans lournal of Reproductive Immunology 34 76-77.

Tremellen KP, Seamark RF and Robertson SA (1998) Seminal transforming growth factor beta 1 stimulates granulocyte-macrophage colony-stimulating factor 
production and inflammatory cell recruitment in the murine uterus Biology of Reproduction 58 1217-1225.

Tremellen KP, Valbuena D, Landeras 1, Ballesteros A, Martinez I, Mendoza S, Norman RJ, Robertson SA and Simon $C(2000)$ The effect of intercourse on pregnancy rates during assisted human reproduction Human Reproduction 15 2653-2658.

Vallet JL, Leymaster KA and Christenson RK (2002) The influence of uterine function on embryo and foetal Survival Journal of Animal Science 80 E115-E125.

Waberski D, Sudhoff H, Hahn T, Jungblut PW, Kallweit E, Calvete J, Ensslin M, Hoppen HO, Wintergalen N, Weitze KF and Topfer-Petersen E (1995) Advanced ovulation in gilts by the intrauterine application of a low molecular mass pronase-sensitive fraction of boar seminal plasma Journal of Reproduction and Fertility 105 247-252.

Watson JG, Carroll J and Chaykin S (1983) Reproduction in mice: The fate of spermatozoa not involved in fertilization Gamete Research 7 75-84.
Weiner HL (2001) Oral tolerance: immune mechanisms and the generation of Th3-type TGF-beta-secreting regulatory cells Microbes and infection $3947-954$.

Weitze KF, Habeck O, Willmen T and Waberski D (1990) Interaction between inseminate, uterine and ovarian function in the sow. II. Investigations into influencing ovulation by use of sperm-free media Reproduction in Domestic Animals 29 433-443.

Yoshida S, Ono M, Shono T, Izumi H, Ishibashi T, Suzuki $H$ and Kuwano $M$ (1997) Involvement of interleukin8 , vascular endothelial growth factor, and basic fibroblast growth factor in tumor necrosis factor alphadependent angiogenesis Molecular and Cell Biology 17 4015-4023.

Zareie M, McKay DM, Kovarik GG and Perdue $\mathrm{MH}$ (1998) Monocyte/macrophages evoke epithelial dysfunction: indirect role of tumor necrosis factor-alpha American lournal of Physiology 275 C932-939. 